\title{
Study on Problems and Countermeasures in Human Resource Development among Urban Community Sports Volunteers --- A Case Study of Urban Community in Qingdao
}

\author{
Yun Ma \\ Physical Education Department, Qingdao University of Science and Technology \\ Qingdao 266042, China \\ E-mail: pemayun@163.com
}

Received: March 3, 2011 Accepted: March 20, $2011 \quad$ doi:10.5539/ass.v7n7p220

\begin{abstract}
It discussed the problems and countermeasures in human resources development among sports volunteers in Qingdao community and aimed at offering reference for development of human resource development level of sports volunteers in communities in China. This article revealed some problems as below: scarcity of understanding in volunteer activities, lack of investment in human resource development of community sports volunteers, deficiency of training system among community sports volunteers and imperfect human resource incentive mechanism among community sports volunteers, which are the major problems existing in human resource development in Qingdao community sports volunteers. It put forward the following countermeasures and suggestions: enhancing emphasis on the community sports volunteer service, supporting the community sports volunteer organization development, improving the legal rules and disciplines in activities of community sports volunteers, strengthening the strength of investment in human resource development of community sports volunteers, enhancing cultivation on volunteers in university and college, setting up the training system for social sports volunteers and establishing stimulation and supervision mechanism on sports volunteers, etc.
\end{abstract}

Keywords: Community sports, Volunteers, Human resource development, Qingdao

Community sports volunteers are the footstone for development of the public sports. In human resources of community sports, the development and improvement degree of human resources of community sports volunteers plays an extremely important role in development of human resources of community sports. However, a general survey on the status quo of human resources of urban community sports at present, it is found that there are quite a lot of problems and disadvantages that can not be ignored any more. Given this situation, this research attempts to take urban community in Qingdao as the case study and conducts research on the problems and countermeasures in human resource development of community sports volunteers in order to offer reference for developmental level of human resources in community sports in China.

\section{Research object and research method}

\subsection{Research object}

This research takes the development problem of human resources of Qingdao urban community sports volunteers as the research object.

\subsection{Research method}

This study mainly employs the questionnaire survey method that is usually used in sociology. According to the principle and method of stratified sampling, this study takes the seven districts in Qingdao as a whole study entity. The author randomly selected seven district communities from the seven districts and altogether sent out 200 questionnaires, taking back 191 questionnaires, with a recovery rate of $95.6 \%$. After a validity test, there were 183 effective questionnaires, with the effective recovery rate of $91.5 \%$.

\section{Research result and analysis of the result}

2.1 Major problems existing in human resource development among urban community sports volunteers in Qingdao

2.1.1 Improper knowledge in human resources among urban community volunteers 
Considering the experiences in western countries, community sports volunteers are active in community sports activities and play an irreplaceable role in development of community sports. However, relevant departments and leaders have certain gap in recognizing development, positioning, role and developmental necessity of community sports volunteers. According to the survey, among the 183 respondents, $57.4 \%$ respondents thought that organization of relevant departments was not enough and emphasis of leaders was not sufficient, which were the major factors that restrained development of human resources of community sports volunteers, ranking the first in all options. Insufficient recognition brought about deficiency in guiding degree of the job. Some community members were weak in the consciousness of public welfare and in knowledge in behaviors of community sports volunteers and they were random and non-organized in taking part in activities of community sports volunteers, which constrained the standardized, healthy and orderly development of community sports volunteers. On the other hand, some community sports volunteers also had discrepancy in the knowledge of themselves, lacking in the idea of service and in the feeling of participation and consciousness of activities of community sports volunteers, having not found their own position in development of community sports. The issue in recognition directly affected development of human resource of community sports volunteers and also constrained community sports volunteers to play their due role.

\subsubsection{Insufficient investment in human resource development among community sports volunteers}

Investment in human capital is the primary aspect of human resource development. At the initial stage of the development, investment in human capital is more the key to promote the benign development of the newly born concept of community sports volunteers. Human capital of community sports volunteers is the entire value of human resources of community sports volunteers, which is constituted by community sports volunteers and the capacity possessed by these volunteers which, in turn, can enhance their work. It is formed through developmental investment in human resources and this kind of investment usually mainly depends on expenses of education training and expenses of health care as well as expenses of scientific research and technical promotion spent on improvement of productivity. The nation, the enterprise and the individual are the subjects of investment in human capital. Nevertheless, considering developmental investment in human resources among community sports volunteers in Qingdao, their knowledge in importance of the newly born concept of community sports volunteers and there is deficiency in the subject of development, which leads to shortage of investment in development of community sports volunteers at present. Even for a large majority of community sports volunteers, this is nothing more than blankness, which, to a great extent, restrains development of Qingdao community sports volunteers.

\subsubsection{Deficiency of the training system among community sports volunteers}

Cultivation and improvement of the training system of community sports volunteers directly relates with the actual service capacity level of community sports volunteers and whether urban community sports can be developed in a healthy and sustainable way. Strengthening cultivation of the capacity of community sports volunteers can enable them to come to full understanding of the characteristics and forms of activities of volunteers as well as characteristics and rules of community sports job, so as to dedicate oneself to better serving development of community sports. With continuous improvement of the living standard of Qingdao urban community residents and increasing of their consciousness of health, community residents propose newer and higher demand on the quality of community sports volunteers. Thus, community sports volunteers have the desire to further learn knowledge of community sports organization and management and to improve their fitness skills. However, as a result of insufficient knowledge in important of the training on community sports volunteers and vacancy of the developmental subject, the training is lacking that can satisfy this kind of demand. So far, there is no meticulous plan on training of human resources in community sports volunteers in Qingdao, there is no sufficient analysis in demand on development of urban community sports and conservation of talents, and there is no definite target. As a result, the only few training activities become a merely formality and have no means to satisfy the need of continuous development of community sports.

\subsubsection{Imperfect incentive mechanism in human resource of community sports volunteers}

In the process of development of community sports volunteer service, establishment of incentive mechanism is quite important. Realization of sustainable development of community sports volunteers' activities calls for continuous effective incentive on volunteers in practice. Although activities held by Qingdao urban community sports volunteers are on a grand and spectacular scale, the incentive mechanism is seriously in shortage. From the survey conducted in this study, it was also discovered that, $62.8 \%$ investigators thought that the incentive mechanism of human resource of volunteers was not perfect. As those who take part in volunteer service, the volunteers participate in the service with the love heart of dedication and the motive of enriching the spirit, 
which exactly abandons regard of interests in the occupational occasion. Yet, the society should give rewards and returns to service of the volunteers, since only those who help the society and others get incentives, can the community sports volunteer service gets development in a long run. However, an effective talent incentive mechanism has not been set up in Qingdao, while volunteer organizations and volunteer individuals are stimulated based on their experiences, with too many repeated and common incentive factors, lacking in incentive factors that are gradually deepened and affect deeply. Then, flexible innovation is deficient. Quite a lot of social incentive factors are set up by leading institutions and have not called for extensive opinions from the volunteers and let them take part in the design. Thus, the pattern and content of rewarding is single and mechanical, lacking in attraction.

2.1.5 Low degree of development and employment of community sports volunteers, low degree of development of human resources and shortage of supply of talents, which become the huge "bottleneck" that restrains development of Qingdao community sports volunteers

Community sports instructors, sports teachers, sports enthusiasts and students of sports are the precious resources for development of Qingdao community sports career. Currently, community sports instructors (sports teachers) in colleges and universities are relatively abundant, which don't include the sports core members and students of the sports major in colleges and universities who have solid sports technical skills, rich sports theoretical knowledge and abundant physical strength and energy, so they are totally qualified to hold the position of community sports volunteers. If they are encouraged to participate in the team of community sports volunteers, then human resources of Qingdao community sports volunteers are quite abundant. In the meanwhile, as for students, they are provided with the opportunities to internship practice and come to contact with the society and know about the society. However, this important sports resource has not got effectively developed and is even ignored. The degree of participation by sports teachers and students in university and technical secondary schools in community sports volunteer service is still relatively low.

\subsection{Countermeasures and suggestions for development of human resources of urban community sports volunteers}

\subsubsection{To enhance emphasis on the volunteer service of community sports}

Insufficient knowledge in community sports volunteer service restrains its role in construction of the community. To put first things first, it is to strengthen education and organize with emphasis functional departments concerned, street offices and relevant personnel in community neighborhood committee to learn deeply knowledge related with community sports volunteer service and to enable them to have comprehensive and in-depth understanding in community sports volunteer service. Secondly, to strengthen education on community residents and to cultivate the consciousness of participation among community residents. Thirdly, community sports volunteers themselves should also make clear some misunderstandings in knowledge. At the same time, they should improve knowledge of the entire society in the importance of community sports volunteer service and take advantages of all sorts of media, means and methods to reinforce vigor of propaganda of community sports volunteer service. In one word, in order for community sports volunteers to develop themselves, the first thing to do is to break through the "bottleneck" in the concept. Governmental departments at all levels have to come to full recognition of the property and role of community sports volunteer service and the position of the service in construction of the community, so as to take positive measures in practice to cultivate and develop community sports volunteer service. As for community residents, they take an initiative to take part in all kinds of activities in community sports volunteer service after they have realized the relationship between community sports volunteer service and themselves. As for the community sports volunteer service itself, its position in the construction of the community should be defined so as to positively expand service and enlarge social influential strength.

\subsubsection{To support development of community sports volunteers organization}

For the time being, the mode of "small government and large society" in China is gradually taking its shape. Construction of organizations that positively support volunteers is not only to make up for requirement of occupational vacancy of "limited government", but is an important measure to adapt to development and expansion of Qingdao social sports in the future. Therefore, sports functional departments at all levels of Qingdao municipal government ought to set about attaching importance on and studying this newly born thing and positively support development of community sports volunteers' organization. They should not only give necessary support to their development in terms of policy, funds and public opinions, but should also give vigorous commendation on their work performance. Activities by community sports organizers belong to the non-governmental voluntary activities. However, in China, this kind of non-governmental organization lags 
behind in terms of its survival space and developmental capacity, which calls for necessary institutional guarantee to facilitate its survival and development.

\subsubsection{To strengthen investment in development of human resources of community sports volunteers}

Relevant departments should take an initiative to strengthen vigor of investment in human resources of community sports volunteers, especially the vigor of investment in community sports volunteers among university students. In addition to enlarging investment in human resources development of community sports volunteers and improvement of investment efficiency, the government should also mobilize and encourage all fields in the society to take part in development of human resources in community sports volunteers by all sorts of means, so as to speed up the step and vigor of cultivation of human resources of community sports volunteers, reduce the burden of governmental finance and achieve the purpose of financing from all aspects and making investment in development of human resources of community sports volunteers.

\subsubsection{To vigorously cultivate volunteer groups in colleges and universities}

The government ought to construct the Olympic volunteer service community by taking university as the center, cultivate the principles of selfless dedication and professional ethics, converge human resources and continue to serve the Olympic Games and the society. All volunteer associations in all universities should combine with local sports department to form a volunteer database through the Committee of Communist Youth League of the university, so as to offer information about volunteers in time and provide guidance and exchange through network training.

\subsubsection{To set up training system for social sports volunteers}

We have to strengthen cultivation of the capacity of community sports volunteers and let them fully understand characteristics and patterns of volunteer activities as well as characteristics and rules of social sports work so as to dedicate their own power to better service for development of social sports. Usually, we can hold all sorts of emergency training classes, regular and irregular short-term skill training classes free of charge, organize an informal discussion and communication and invite relevant experts to guide and help volunteers, which can strengthen the actual service capacity and level of community sports volunteers.

\subsubsection{To optimize allocation of human resources of community sports volunteers}

Allocation of human resources of community sports volunteers is the significant approach to realize optimized combination of human and things and improve usage efficiency and employment value of human resources of community sports volunteers. Allocation of human resources of community sports volunteers is a consecutive process and its purpose is to resort to all sorts of allocation approaches and means to adjust distribution of human resources of community sports volunteers in different regions, departments and all kinds of usage directions, to pursue rationalization and scientificalness so as to generate a work system with high efficiency and enable ach community to work according to their ability. At the same time, allocation of human resources of community sports volunteers is likely to give full play to the optimal combination advantage of the group of human resources of community sports volunteers. The effects are self-evident that are brought through improvement of allocation of human resources of community sports volunteers and encourage and direct human resource flow of community sports volunteers.

\subsubsection{To set up incentive and supervision mechanism for sports volunteers}

Sustainable development of social sports volunteers calls for continuous effective incentive on volunteers in practice. Besides, volunteers should get some returns for their voluntary service activities in terms of material. For instance, offering of volunteer service and sharing of volunteer service can be combined together, a particular account can be set up for volunteers to offer and share volunteer service and their situation of volunteer service work for sports activities, competition and daily work can be put on record and taken out for usage when they need to provide assistance. Since sports volunteer organization is a brand-new field, so far, there has not had any ready-made supervision system that can be employed and borrowed. Thus, we have to learn successful experiences in the international society, especially learn and come to know about the public responsibilities of public welfare institutions in the international society and supervision mechanism and theories, such as, legal framework, government and social supervision, environmental constraint and self-discipline mechanism of public welfare institutions, etc.

\section{Conclusion}

Community sports volunteers are the footstone for development of the public sports. In human resources of community sports, the development and improvement degree of human resources of community sports 
volunteers plays an extremely important role in development of human resources of community sports. However, a general survey on the status quo of human resources of urban community sports at present, it is found that there are quite a lot of problems and disadvantages that can not be ignored in human resources of Qingdao urban community sports volunteers. Development of human resources of Qingdao urban community sports volunteers has not had its due performance. According to this research, we can look into the general situation of Chinese urban communities from the problems existing in human resources of Qingdao urban community sports volunteers, which might have the general significance of further promotion to countermeasures of development of human resources of Qingdao urban community sports volunteers.

\section{References}

Ai, Jun. (2005). Summary and Enlightenment of Cultivation of Sports Volunteers in Western Countries. Journal of Physical Education, 12(2).

Ding, Yuanzhu et al. (2001). Study, Style, Evaluation and Management of Volunteer Activities. Qingdal: Tianjin People's Publishing House, pp.1-4.

Ren, Hai. (1998). Developmental Mode of Urban Community Sports in China. Sports and Science, (4):1-6.

Xiao, Linpeng, Sun, Ronghui, Yang, Junfeng et al. (2005). Survey on the Status Quo of Public Sports in Qingdao.

Xiao, Linpeng. (2005). Social Sports Management. Beijing: Beijing Sport University Press, p.8. 